\title{
Analysis of the Bulk Coal Transport State of a Scraper Conveyor Using the Discrete Element Method
}

\author{
Xuewen Wang* - Bo Li - Zhaojian Yang \\ Taiyuan University of Technology, College of Mechanical Engineering, \\ Shanxi Key Laboratory of Fully Mechanized Coal Mining Equipment, China
}

\begin{abstract}
A scraper conveyor is the main transport equipment in a coal mine, and its condition considerably influences the production capacity and profitability of the enterprise. In this study, the discrete element method (DEM) was used to study the interaction between the scraper conveyor and bulk coal. The particle size and velocity distributions of bulk coal were analysed at different transport velocities, transport angles, feed velocities and mining heights by changing the transport conditions of the conveyor. The influence of the transport velocity, coefficient of static friction between particles and mass flow rate were also studied. The results showed that the particle size distribution of bulk coal is mostly unrelated to the transport state parameters in the stable transport stage. Large particles gather at higher positions, whereas small particles gather at lower positions. The speed of bulk coal in the front area of the scraper was equal to the velocity of the scraper, whereas the coal in other locations had a lower speed. The mass flow rate of the bulk coal increased with increasing transport velocity and reached its peak when the coefficient of static friction between particles was 0.4 .

Keywords: scraper conveyor, bulk coal, discrete element method, mass flow rate

Highlights

- $\quad$ The discrete element model developed can simulate bulk coal-scraper conveyor interactions.

- $\quad$ The bulk coal size distribution had little relation with the transport state parameters at smooth transport stage.

- $\quad$ Big particles gathered at the upper position while the small ones at the lower position on the scraper conveyor.

- Bulk coal mass flow rate increased as the transport velocity increased.

- $\quad$ Bulk coal mass flow rate reached the peak when the static friction coefficient between particles was 0.4.
\end{abstract}

\section{INTRODUCTION}

As the main transport equipment for fully mechanized coal caving, a scraper conveyor is not only the coal transport machine but also the moving pivot of the hydraulic support and the orbit of the shearers. The rationale behind the design of the scraper conveyor and its reliability directly affect the production efficiency of a fully mechanized coal mining system [1] and [2]. Current research on scraper conveyors mainly focuses on how to improve their power, capacity, life, safety and applicability in various working conditions. Significant attention has been paid to the structure and function of the scraper conveyor itself [3] to [6]. Few studies have focused on the material characteristics during the transport stage and the interaction between bulk coal and the scraper conveyor, and even fewer studies have provided a precise relationship between the transport of bulk coal and the running conditions of the scraper conveyor. This lack of research inevitably leads to deviations in safety, reliability and transport efficiency that affect the entire material transport process.

Three-dimensional optimization, simulation and dynamic design have become important techniques in modern mechanical design with the rapid development of computer technology and modern design methods
[7] to [9]. Previous studies have mainly used finite element methods (FEMs) for the design and analysis of scraper conveyors. The bulk coal in the chute is represented using either a continuum model or directly added force on the chute, and then, the mechanics are established using the FEM. Optimization methods are applied after simulation and analysis using FEM [10] to [13]. A systems analysis, including mechanical analysis of the shearer and chute, was conducted by Chen et al. [14] to study the stress conditions of the chute; the maximum stress was obtained using ANSYS, a software package based on an FEM. Ren and Chen [15] studied the rack rail of a scraper conveyor using ANSYS, and their conclusions provided a theoretical basis for the optimal structural design of the rack rail.

Particles of granular matter interact with themselves and with the machine [16]; thus, it is difficult to obtain meaningful results using traditional continuum mechanics methods, such as FEM. Therefore, the discrete element method (DEM) was introduced to better study the internal and external interaction mechanics of materials and to obtain reliable results. The DEM is a numerical method that was proposed by Cundall and Strack [17] and Cundall [18] and is based on the principles of molecular dynamics. The method was first used 
to study complex problems, such as rock mechanics. A DEM is a collection of rigid elements, which is more in accordance with the properties of granular material than continuum theory. The method has been successfully applied in coal mining, geotechnical engineering, the chemical industry, agriculture and other fields [19] to [23]. There are many applications in bulk solids transportation. Lim et al. [24] simulated vertical and horizontal solid particle transport in a pneumatic conveyance using the DEM and computational fluid dynamics. The simulated and experimental results corresponded well with those reported previously. Zuo et al. [25] studied the dynamic characteristics of bulk materials (e.g., agricultural products) during the process of sudden braking using the DEM. The dynamic forces acting on the front wall of a truck by the bulk material under different conditions were studied, which provided new ideas for truck design. Katterfeld and Gröger [26] studied the loading and unloading process of a bucket elevator and scraper conveyor using the same method. Additionaly, Katterfeld et al. [27] developed an auxiliary design for a high-flow transfer station using the DEM and provided qualitative and quantitative verification of the numerical simulation. Simsek and Wirtz [28] studied the mixing process of a thin layer of particles on a vibrating conveyor and investigated the phenomena of particle flow and dispersion using the DEM. Hastie and Wypych [29] compared different methods, such as the continuous medium method, DEM and test experiments, to predict the particle flow phenomenon in the chute. Derakhshani et al. [30] used the DEM to study the mechanical behaviour between particles and the interaction between the belt conveyor and particles. The particle flow field was simulated using computational fluid dynamics, and the entrainment phenomenon was studied to help optimize the dust control system. The above research applied the DEM to the study of bulk materials; however, few studies have focused on the scraper conveyor.

The objectives of this study were as follows: (1) establish an interaction model between bulk coal and the scraper conveyor using the software EDEM; (2) study the particle size distribution and velocity of coal under different conditions, such as differences in transport velocity, transport angle, feed velocity and mining height; and (3) study the influences of the transport velocity and coefficient of static friction on the mass flow rate.

\section{METHODOLOGY}

\subsection{Model Scraper Conveyor}

The scraper conveyor mainly consists of a head, spill plate, chute, scraper, chain and tail (Fig. 1). The scraper conveyor model used in this study was a production model. Its design length was $200 \mathrm{~m}$, the rated transport capacity was $416.7 \mathrm{~kg} / \mathrm{s}$, the speed of the scraper chain was $1.1 \mathrm{~m} / \mathrm{s}$ and the scraper spacing was $1,008 \mathrm{~mm}$.

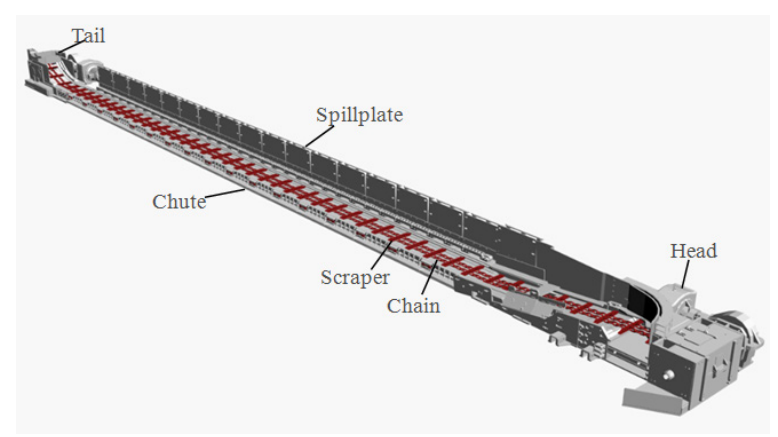

Fig. 1. Structure of a scraper conveyor

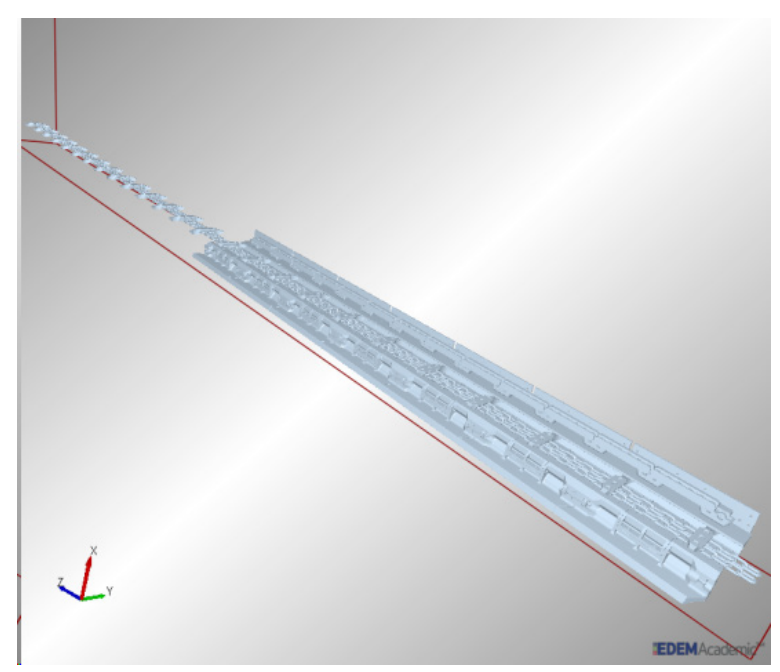

Fig. 2. Model of the chute

Table 1. Material parameters of the chute [31]

\begin{tabular}{lc}
\hline Material parameters & High manganese steel \\
\hline Poisson's ratio & 0.3 \\
\hline Shear modulus $[\mathrm{Pa}]$ & $7 \times 1010$ \\
\hline Density $\left[\mathrm{kg} / \mathrm{m}^{3}\right]$ & 7800 \\
\hline
\end{tabular}

The modelling function of EDEM is relatively simple. Thus, it is difficult to satisfy the modelling requirements of a complex geometry, such as that of a scraper conveyor. Therefore, the three-dimensional 
model was first established in NX7.5 UG software (Siemens PLM Software, Munich, Germany) and then imported into EDEM to perform the simulation. Because this study focused mainly on the transport state and related properties of the bulk coal, the scraper conveyor model was simplified by removing the head and tail, retaining only the chute; this also improved the speed of the calculations. The scraper chain and scraper were extended to ensure that a sufficient number of scrapers were in motion on the chute during the simulation.

Different file formats can be imported into EDEM. Here, the STEP format was chosen to ensure the integrity of the data, the model, the product life cycle and other aspects due to the complex geometry of the scraper conveyor. The established model and the material parameters of the chute are shown in Fig. 2 and Table 1, respectively.

\subsection{Model Bulk Coal}

Two main types of contact were applied in this model, namely, the contact between coal particles and the contact between coal and the chute. Coal particle breakage and deformation occurs under actual conditions, and numerous particle collisions will occur simultaneously. A soft ball model was selected as the mechanical model in this study to accurately reflect these actual conditions.

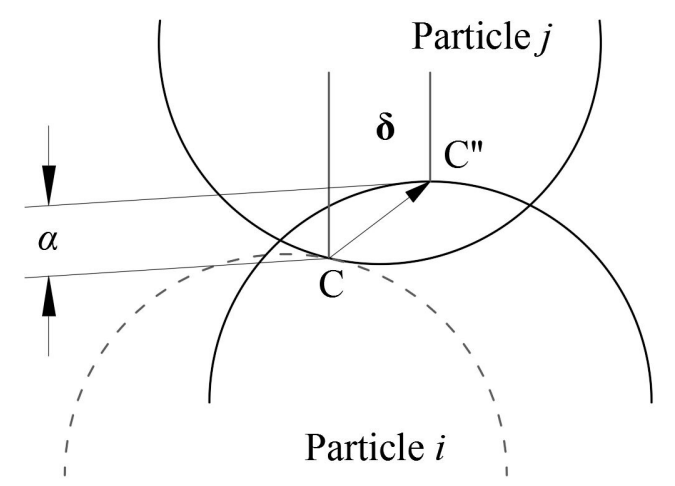

Fig. 3. Model of two contact soft balls

As shown in Fig. 3, particle $i$ comes into contact with particle $j$ at point $\mathrm{C}$ under external forces or inertia. The dotted line indicates the original position of particle $i$. With the relative motion of the two particles, the surfaces of the particles gradually deform and the contact force increases. However, details of the deformation were not considered in the soft sphere model, and the contact force was obtained based on the normal overlap $\alpha$ and tangential displacement $\boldsymbol{\delta}$.

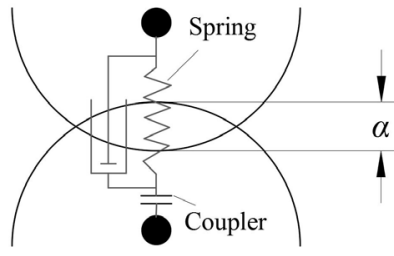

a)

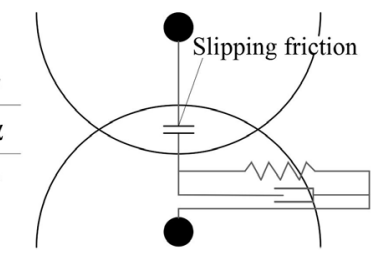

b)
Fig. 4. Simplified model of contact force between particles: a) normal force, and $b$ ) tangential force

The soft ball model consisted of a spring, damper, slider and coupler between two particles. A coupler was used to determine the particle pairing relationship of two particles in contact. If the tangential force exceeds the yield value, the two particles will slide under the effects of the normal force and friction in the tangential direction. The elastic coefficient $k$, the damping coefficient $c$ and other parameters were introduced to quantify the effect of the spring, damper and slider (Fig. 4).

The normal force $\mathbf{F}_{n i j}$ was the resultant of the elastic and damping forces acting on particle $i$, as shown in Figs. 3 and 4. According to Hertz contact theory, $\mathbf{F}_{n i j}$ is expressed as follows:

$$
\mathbf{F}_{n i j}=\left(-k_{n} \alpha^{2 / 3}-c_{n} \mathbf{v}_{i j} \cdot \mathbf{n}\right) \mathbf{n} .
$$

The tangential force $F_{t i j}$ is expressed as:

$$
\mathbf{F}_{t i j}=-k_{t} \boldsymbol{\delta}-c_{t} \mathbf{v}_{c t},
$$

where $k_{t}$ is the tangential elastic coefficient, $c_{t}$ is the tangential damping coefficient, $\mathbf{v}_{c t}$ is the slip velocity at the contact point, and $\boldsymbol{\delta}$ is the tangential displacement at the contact point.

Particle generation is critical in the simulation process and greatly affects the simulation results. Bulk coal differs from other bulk materials that have rather homogenous particle shapes, such as chemical fertilizers or grains, because of the uncertainty in the shapes cut by the shearer. It is difficult to define the true shape of coal particles in 3D modelling software, and there is no representative shape. Therefore, to simplify the calculation and represent the actual situation as closely as possible, a multiple round surface filling method was used in EDEM to build the bulk coal model. A model of a standard coal particle was constructed using four combined spheres (Fig. 5); the model was $95.11 \mathrm{~mm}$ long, $85.59 \mathrm{~mm}$ wide and $80.05 \mathrm{~mm}$ high. Particles with three different diameters were used to study the size distribution of bulk coal; the dimensions were $0.5,1$ and 1.3 times that of the standard particle size. Particles with different sizes were generated randomly by a particle 
factory to ensure that the bulk coal fell into the chute in a mixing state. The properties of bulk coal are provided in Table 2 [31].

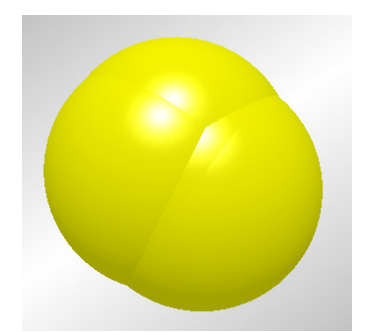

Fig. 5. Bulk coal model

The weight of the standard coal particle that was modelled was $0.56 \mathrm{~kg}$, the volume was $3.53 \times 10^{-4} \mathrm{~m}^{3}$ and the moment of inertia relative to $\mathrm{X}, \mathrm{Y}$, and $\mathrm{Z}$ axes was $4.01 \times 10^{-4} \mathrm{kgm}^{2}, 4.48 \times 10^{-4} \mathrm{kgm}^{2}$ and $4.65 \times 10^{-4}$ $\mathrm{kgm}^{2}$, respectively

Table 2. Property of bulk coal [32]

\begin{tabular}{lc}
\hline Particle material properties & coal \\
\hline Poisson's ratio & 0.25 \\
\hline Shear modulus $[\mathrm{Pa}]$ & $1 \times 107$ \\
\hline Density $\left[\mathrm{kg} / \mathrm{m}^{3}\right]$ & 1600 \\
\hline
\end{tabular}

\subsection{Contact and Transport Model}

Based on analysis of the mechanical model and actual working conditions, the Hertz-Mindlin no slip contact model was used in this study; the contact parameters of this model are provided in Table 3 [32].

Table 3. Contact parameters [32]

\begin{tabular}{lc}
\hline Elastic restitution coefficient between bulk coal particles & 0.5 \\
\hline Static friction coefficient between bulk coal particles & 0.6 \\
\hline Dynamic friction coefficient between bulk coal particles & 0.05 \\
\hline Elastic restitution coefficient between bulk coal and the chute & 0.5 \\
\hline Static friction coefficient between bulk coal and the chute & 0.4 \\
\hline Dynamic friction coefficient between bulk coal and the chute & 0.05 \\
\hline
\end{tabular}

This study focused on the motion characteristics of bulk coal in the chute; thus, the simulation included the cutting of bulk coal by the shearer, coal falling into the chute and transport of the coal by the scraper conveyor. Based on actual production, the particle factory was set at the original position in the upper part of the scraper and parallel to the bottom of the chute. The process of the shearer cutting coal was simulated by the particle factory producing bulk coal; the mining height was $2.6 \mathrm{~m}, 5 \mathrm{~m}$, or $5.5 \mathrm{~m}$ based on the position of the actual shearer. The particle factory was rectangular in shape, with a length of $2.5 \mathrm{~m}$ along the chute and a width of $0.755 \mathrm{~m}$.

\subsection{Simulation Parameters}

The stable state was established as the reference state, and the parameters were changed when studying the scraper conveyor under different working conditions. The main simulation parameters in this study were the transport angle, transport velocity, feed velocity and mining height. The main parameters of the stable state are provided in Table 4.

Table 4. Main parameters of the stable state

\begin{tabular}{lc}
\hline Transport state parameters & Stable \\
\hline Transport angle $\left[{ }^{\circ}\right]$ & 0 \\
\hline Transport velocity [m/s] & 1.1 \\
\hline Feed velocity [m/s] & 3.44 \\
\hline Mining height [m] & 5.5 \\
\hline
\end{tabular}

The parameters of the stable state were based on the relevant parameters of an actual scraper conveyor and shearer (Table 5). The transport velocity was the rated speed of the scraper conveyor, and the feed velocity was converted from the rated rotational speed of the shearer. The initial velocity of the bulk coal was set based on the rated rotational speed of the shearer.

Table 5. Related parameters of the electric haulage shearer

\begin{tabular}{lc}
\hline Mining height range $[\mathrm{m}]$ & 2.6 to 5.5 \\
\hline Drum diameter $[\mathrm{mm}]$ & 2,500 \\
\hline Drum rotation speed $[\mathrm{m} / \mathrm{s}]$ & 3.44 \\
\hline
\end{tabular}

In this study, the fixed time step in EDEM was set as $8.59 \times 10^{-5} \mathrm{~s}$, which was $10 \%$ of the Rayleigh time step, and the total simulation time was $15 \mathrm{~s}$. The grid size in the simulation area was adjusted according to the related preprocessing parameters. To obtain accurate results while retaining a high simulation efficiency, the number of grid units was set close to but less than $1 \times 10^{5}$. Therefore, the grid size was set to 6.89 times of the particles' minimum radius, and the simulation area was divided into 92,565 grid units.

Bulk coal was generated dynamically from $t=$ $0 \mathrm{~s}$ to $t=15 \mathrm{~s}$ with a fixed particle size. Aside from gravity, an initial velocity was added to coal particles to simulate the initial speed of coal brought about by the rotating shearer. The direction of the initial particle velocity was set at a $45^{\circ}$ downward slope. Particle factories simulated the generation of coal 
cut by the shearers. To ensure that the same number of particles were created for the three different sizes, the speed at which particles were generated by the three factories was calculated based on the ratios of the dimensions of the different particles. The speed at which the particle factories generated particles was set according to the rated transport capacity of an actual scraper conveyor, which was $416.7 \mathrm{~kg} / \mathrm{s}$ in this study. The particle generation speeds of the three particle factories are provided in Table 6.

Table 6. Particle generation speed of each particle factory

\begin{tabular}{lc}
\hline Particle factory & Generation speed $[\mathrm{kg} / \mathrm{s}]$ \\
\hline 0.5 times the standard particle size & 15.65 \\
\hline 1 times the standard particle size & 125.23 \\
\hline 1.3 times the standard particle size & 275.12 \\
\hline
\end{tabular}

\subsection{Working State Simulation}

The stable state is the normal and stable working condition of a scraper conveyor when transporting bulk coal. For a given type of coal, the controllable factors affecting the transport state include the transport angle, transport velocity, feed velocity and mining height. There are fewer uncontrollable factors in the stable state, and different transport states were simulated. The simulated results were then compared with those in the stable state to study the transport state under different working conditions.

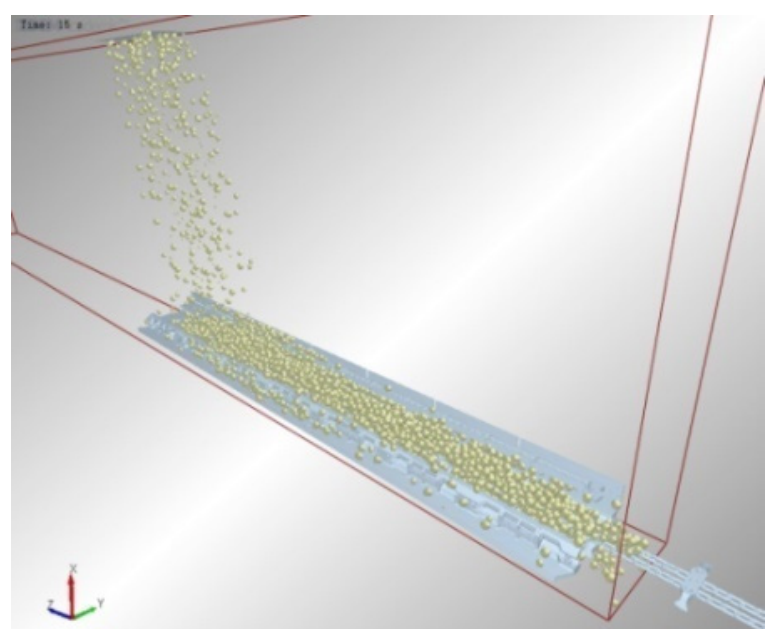

Fig. 6. Simulation of the stable state

The simulation begins with the particle factory generating particles. Then, the bulk coal falls into the chute and is transported from one side of the scraper to the other (Fig. 6). The interaction model was established based on the model of the chute (Fig. 2) and the bulk coal (Fig. 5). The entire simulation lasted for $15 \mathrm{~s}$.

When studying the transport state under different velocities, the running direction of the scraper and the chain was constrained to be parallel to the bottom of the chute. In the actual situation, the velocity of the chain was changed in a micro wave because of rotation of the sprocket. For the limitation of the software and the purpose of simplifying the simulation, the scraper and scraper chain were set in the uniform linear motion during the entire simulation. Then, the bulk coal was pushed to move by the scraper. The transport velocities are shown in Table 7.

Table 7. Transport velocities

\begin{tabular}{ll}
\hline Stable state $[\mathrm{m} / \mathrm{s}]$ & 1.1 \\
\hline Speed $1[\mathrm{~m} / \mathrm{s}]$ & 0.8 \\
\hline Speed $2[\mathrm{~m} / \mathrm{s}]$ & 0.5 \\
\hline
\end{tabular}

To study the transport state with different transport angles, the angle was adjusted by changing the direction of gravity because the angle of the scraper conveyor could not be adjusted directly. The gravitational direction was set by adjusting the values of its components in the $\mathrm{X}, \mathrm{Y}$, and $\mathrm{Z}$ directions.

In the stable state, the direction of gravity was perpendicular to the chute. The other two angles were set at the limiting angles of the scraper conveyor: inclined upward $25^{\circ}$ and inclined downward $20^{\circ}$. The direction of gravity is shown in Table 8 .

Table 8. Parameters of gravity under different transport angle conditions

\begin{tabular}{lc}
\hline Transport angle & Direction vector \\
\hline $0^{\circ}$ & $(-9.809,0,-0.13987)$ \\
\hline Inclined upward $25^{\circ}$ & $(-8.9491,0,4.0187)$ \\
\hline Inclined downward 20 & $(-9.1696,0,-3.4863)$ \\
\hline
\end{tabular}

Table 9. Different feed velocities

\begin{tabular}{lc}
\hline Velocity $[\mathrm{m} / \mathrm{s}]$ & Coordinate \\
\hline 3.44 & $(-2.435,0,-2.435)$ \\
\hline 2.12 & $(-1.5,0,-1.5)$ \\
\hline 1.41 & $(-1,0,-1)$ \\
\hline
\end{tabular}

To study the influence of feed velocity on the transport state, the magnitude of the initial particle velocity was changed while leaving its direction of motion unchanged. The components of the initial velocity in the $\mathrm{X}, \mathrm{Y}$, and $\mathrm{Z}$ directions are provided in Table 9. The three particle factories maintained the same initial particle velocity. The initial velocity of 
the stable state was $3.44 \mathrm{~m} / \mathrm{s}$ and was set to $2.12 \mathrm{~m} / \mathrm{s}$ and $1.41 \mathrm{~m} / \mathrm{s}$ in the other two states.

In the study of different mining heights, the position of the particle factory needed to be adjusted. The mining height was $5.5 \mathrm{~m}$ in the stable state and 5 $\mathrm{m}$ and $2.6 \mathrm{~m}$ in the other two states (Table 10).

Table 10. Different mining heights

\begin{tabular}{lc}
\hline Stable state $[\mathrm{m}]$ & 5.5 \\
\hline Height $1[\mathrm{~m}]$ & 5 \\
\hline Height $2[\mathrm{~m}]$ & 2.6 \\
\hline
\end{tabular}

\subsection{Factors Influencing the Mass Flow Rate}

Transport capacity is an important parameter in the design of a scraper conveyor and directly determines the quality of the scraper conveyor. Although the mass flow rate refers to the mass flow per unit time, the value can directly reflect the transport capacity of the scraper conveyor as well. Thus, research on the mass flow rate is critical for improving the transportation capacity of a scraper conveyor, optimizing its structure and reducing unnecessary energy dissipation. The model for calculating the transport capacity in actual production is shown in Fig. 7, which was screenshot of the scraper conveyor during transportation. Assuming that the coal on the scraper conveyor will not spill out, the cross section of the coal can be divided into several sections. The percentages shown in Fig. 7 are the ratios of coal transport speed to the chain speed. The coal speed is closer to the chain speed as the coal getting closer to the chain.

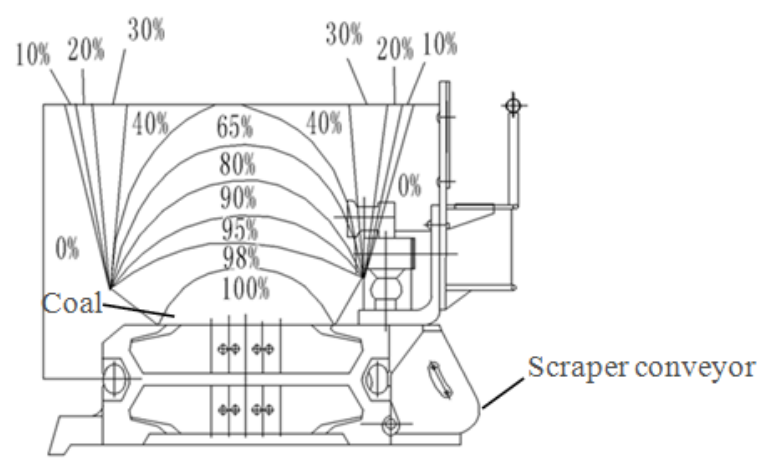

Fig. 7. Model for calculating capacity

The equation for computing the transport capacity is given by:

$$
Q=3.6 \times 10^{6} \times\left(\sum A_{n} i_{n}\right) v_{n} \rho
$$

where $Q$ is the transport capacity of the scraper conveyor per hour $[\mathrm{kg} / \mathrm{h}], A_{n}$ is the cross-sectional area of cargo $\left[\mathrm{m}^{2}\right], i_{n}$ is the relative velocity of the cargo section, $v_{n}$ is the running velocity of the scraper chain $[\mathrm{m} / \mathrm{s}]$, and $\rho$ is the bulk coal density $\left[\mathrm{kg} / \mathrm{m}^{3}\right]$.

The mass flow rate through a specified section during the simulation is detected by a sensor in EDEM. Single-factor analysis was applied to study the influence of velocity and the coefficient of static friction on the mass flow rate. When studying the influence of transport velocity on the mass flow rate, the scraper conveyor was confirmed to be working in the stable state. The coefficient of static friction was maintained at 0.6 , and the scraper conveyor was adjusted to work under transport velocities of $(0.2$, $0.5,0.8,1.1,1.4$ and 1.7$) \mathrm{m} / \mathrm{s}$. The mass flow rate was always detected at the same position.

In analysing the influence of the coefficient of static friction between particles on the mass flow rate, the velocity was kept constant, and the coefficient was set at $0,0.2,0.4,0.6$ and 0.8 . Then, the mass flow rate was determined.

\section{RESULTS AND DISCUSSION}

\subsection{Analysis of the Particle Size Distribution}

Bulk coal particles with three diameters were generated to analyse the effects of the particle size distribution. In the simulation, the particles were coloured blue, green and red in order of increasing size (Fig. 8).

The four groups (a, b, c and d) in Fig. 8 correspond to the particle size distributions with different transport velocities, transport angles, feed velocities, and mining heights. The bulk coal was more stable when the scraper conveyor had a lower velocity (Fig. 8a). However, lower velocities affected the production efficiency. The bulk coal becomes unstable as the chute angle is decreased from being inclined upward $25^{\circ}$ to being inclined downward $20^{\circ}$ (Fig. 8b). The feed velocity did not have a considerable effect on the fluctuation of particles in the chute (Fig. $8 \mathrm{c})$. The bulk coal was more stable when the mining height was low (Fig. 8d). Large particles (red) were concentrated on top, whereas small particles (blue) spread out on the bottom. Middle-sized particles were located in the middle section. Therefore, the bulk coal size distribution with large particles on top and small particles at the bottom was not related to the transport velocity, transport angle, feed velocity, or mining height. 


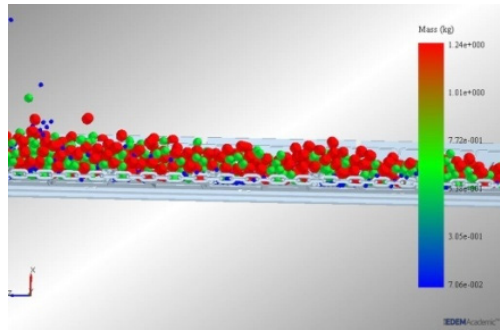

a1) $\mathrm{v} 1=1.1 \mathrm{~m} / \mathrm{s}$

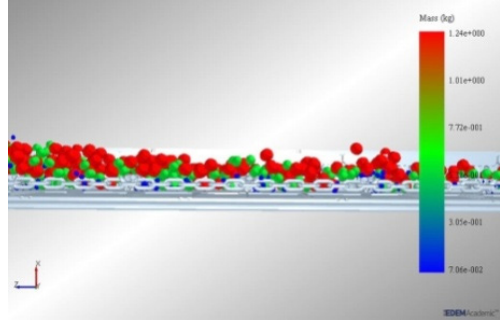

b1) Angle $=$ inclined upward $25^{\circ}$

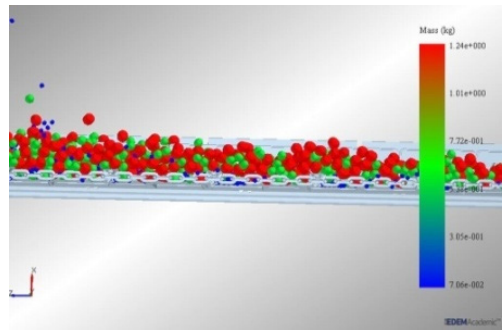

c1) $v 2=3.44 \mathrm{~m} / \mathrm{s}$

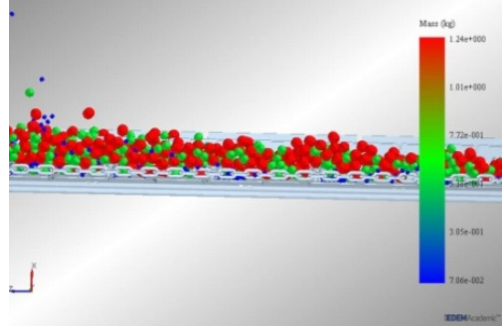

d1) Height $=5.5 \mathrm{~m}$

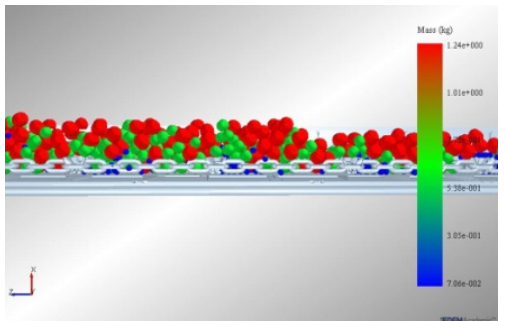

a2) $\mathrm{v} 1=0.8 \mathrm{~m} / \mathrm{s}$

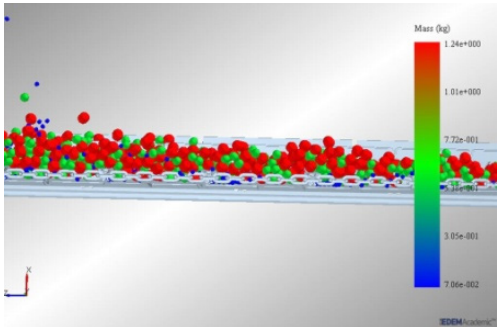

b2) Angle $=0^{\circ}$

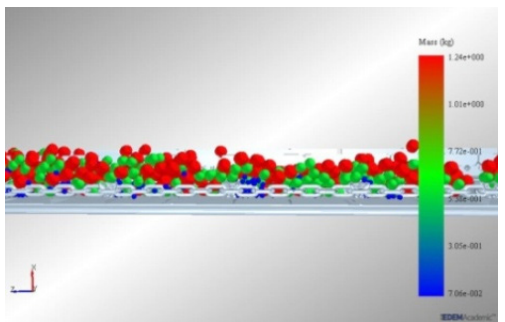

c2) $\mathrm{v} 2=2.12 \mathrm{~m} / \mathrm{s}$

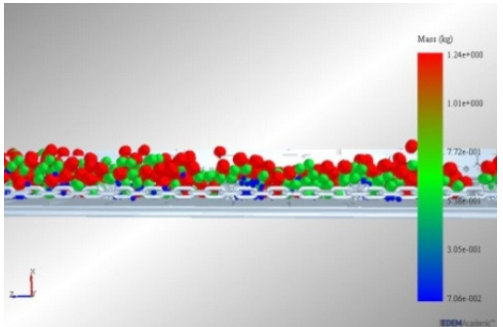

d2) Height $=5 \mathrm{~m}$

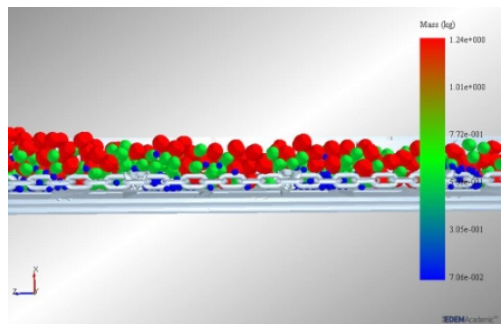

a3) $\mathrm{v} 1=0.5 \mathrm{~m} / \mathrm{s}$

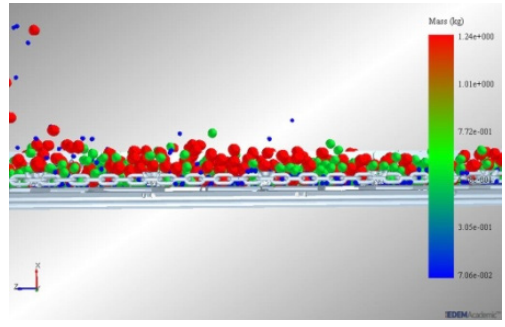

b3) Angle $=$ inclined downward $20^{\circ}$

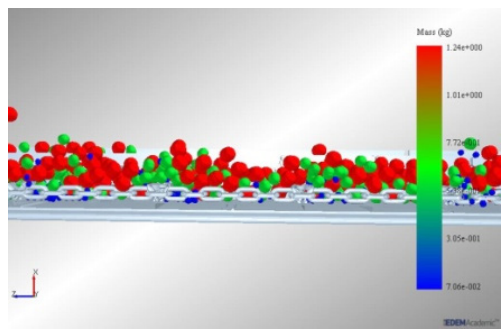

c3) $\mathrm{v} 2=1.41 \mathrm{~m} / \mathrm{s}$

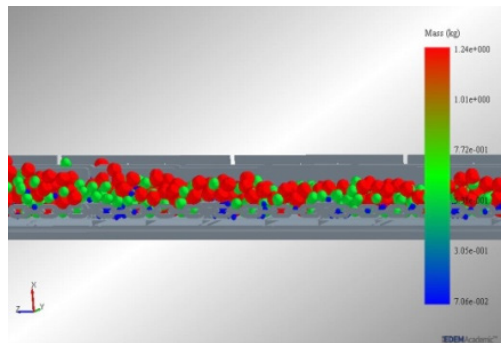

d3) Height $=2.6 \mathrm{~m}$

Fig. 8. Sections showing the particle size distribution under different conditions; a) a1 to a3 different transport velocities; b) different transport angles, c) different feed velocities, and d) different mining heights

\subsection{Velocity Distribution Analysis}

The bulk coal can be displayed in different colours according to the velocity of particles in EDEM. Particles were coloured in order of blue, green and red with increasing velocity (Fig. 9).

The particles in the chute had a lower velocity than particles falling down from the particle factory (Fig. 5). All particles in the chute were blue, within which it was difficult to distinguish the velocity distribution. Thus, the colours of particles in the chute had to be redefined.

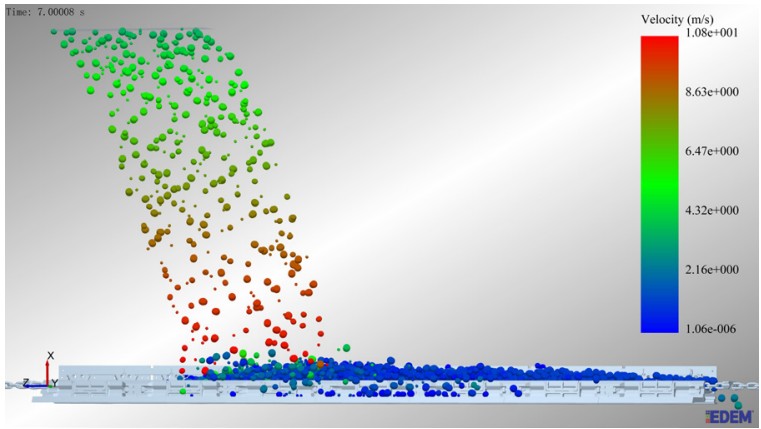

Fig. 9. Particles coloured by velocity (colouring range divided automatically) 


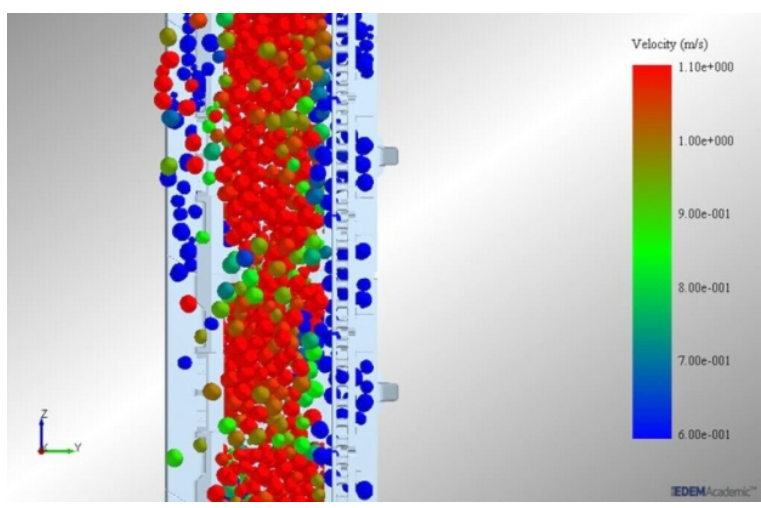

Fig. 10. Distribution of particle velocities (colouring range: $0 \mathrm{~m} / \mathrm{s}$ to $1.1 \mathrm{~m} / \mathrm{s}$ )

Under the attribute colouring label, the minimum and maximum values were set as $0 \mathrm{~m} / \mathrm{s}$ and $1.1 \mathrm{~m} / \mathrm{s}$, respectively. Then, the colouring range was $0 \mathrm{~m} / \mathrm{s}$ to $1.1 \mathrm{~m} / \mathrm{s}$. The particle velocity distribution within the chute is shown in Fig. 10.

The majority of the bulk coal in the middle of the chute had a high velocity, whereas lower velocity particles were distributed on both sides of the chute (Fig. 7).

The range over which velocities were coloured was large, and nearly all of the particles in the chute were red. Thus, it was still difficult to identify the particle velocity distribution. The range of colours was adjusted such that the minimum and maximum values were set at $1.09 \mathrm{~m} / \mathrm{s}$ and $1.1 \mathrm{~m} / \mathrm{s}$, respectively. Longitudinal sections of the particle velocity distribution along the chute were obtained at different positions.

There were differences near the bottom of the chute in that particles close to the scraper had higher velocities than particles farther from the scraper (Figs. $11 \mathrm{a}$ and 11b). Instead of a continuous distribution, the particle velocities exhibited regional concentrations (Fig. 11c). Particles in front of the scraper had the same velocity as the scraper, whereas particles in other locations had lower velocities.

\subsection{Analysis of the Factors Influencing the Mass Flow Rate}

\subsubsection{Effect of Velocity on the Mass Flow Rate}

The mass flow rate increased linearly with the transport velocity, with an $R^{2}$ value of 0.975 , meaning that a higher velocity led to a greater capacity (Fig. 12). However, in actual production, the velocity cannot increase without bound. The power provided by the motor is limited, and equipment wear, energy consumption and noise greatly increase with increases in the transport velocity. Furthermore, the required amount of scraper conveyor material also increases. These factors would greatly increase production costs, which is not conducive to actual production. The speed of the chain typically ranges from $0.6 \mathrm{~m} / \mathrm{s}$ to 1.4 $\mathrm{m} / \mathrm{s}$.

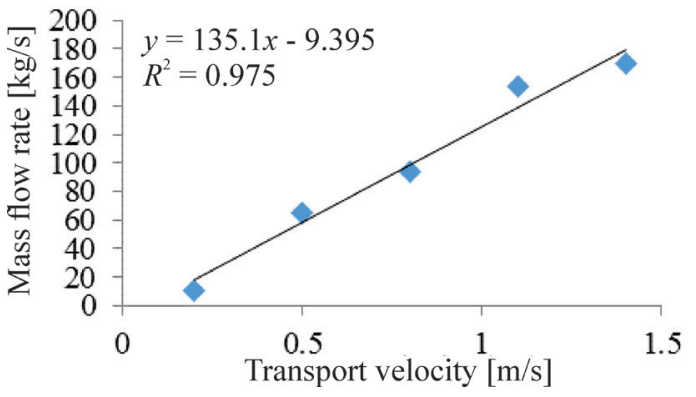

Fig. 12. Mass flow rate under different transport velocities

Therefore, a reasonable transport velocity that will improve the transport capacity and reduce costs as much as possible must be established to achieve the maximum economic benefit. The velocity is also affected by underground operating conditions, the capacity of the scraper conveyor, production requirements and many other conditions, which
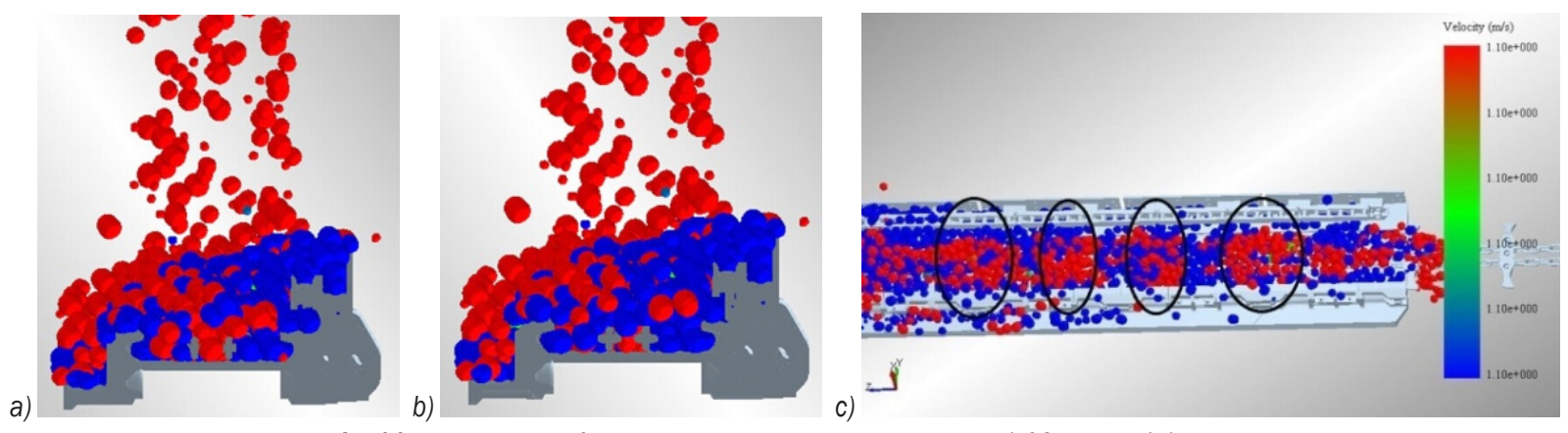

Fig. 11. Distribution of the particle velocity (colouring range: $1.09 \mathrm{~m} / \mathrm{s}$ to $1.1 \mathrm{~m} / \mathrm{s}$ );

a) Iongitudinal section close to the scraper, b) longitudinal section between two scrapers, and c) velocity concentration 
should be analysed based on the actual situation. Such an investigation may provide the relationship between the transport velocities and mass flow rate.

\subsubsection{Effect of the Coefficient of Static Friction on the Mass Flow Rate}

The relationship between the mass flow rate and the coefficient of static friction was fit using a quadratic function (Fig. 13). The mass flow rate increased to a peak $(157.21 \mathrm{~kg} / \mathrm{s})$ as the coefficient of static friction between the particles increased from 0 to 0.4 ; then, the mass flow rate decreased as the coefficient of static friction increased to 0.8 . The scraper conveyor achieved its maximum capacity when the coefficient of static friction between particles was 0.4. Coal particles in the middle and upper part were driven by the static friction from particles at the bottom. If the coefficient of static friction is too small, the static friction would be too small to drive all the particles in the upper part. That's the reason the mass flow rate would increase as the coefficient of static friction increased from 0 to 0.4 . When the static friction is higher than 0.4 , coal particles in the upper part would bear more resistance from coal particles around. The particles stayed at the middle and upper part would roll, which seemed moving backwards compared with the particles pushed by the scraper at the bottom. Therefore, the mass flow rate would decrease when the static friction is higher than 0.4.

In actual practice, static friction between particles, which is determined by the type of coal, cannot be controlled. However, research in this area could provide a basis for predicting coal output depending on the type of coal in a certain mine.

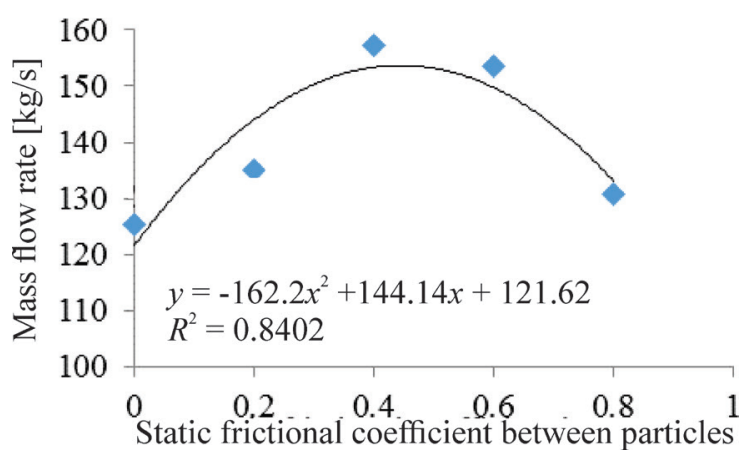

Fig. 13. Mass flow rates with different static friction coefficients

\section{CONCLUSIONS}

The DEM can overcome the deficiencies of the FEM in studying the motions and forces of particles such as bulk coal to provide a more reliable theoretical basis for the research and design of scraper conveyors. The following conclusions were drawn:

1) An interaction model that can simulate the working process of the scraper conveyor was built using EDEM. The operating parameters under different conditions were obtained, which are difficult to acquire experimentally.

2) The particle size distribution was not related to the transport velocity, transport angle, feed velocity, or mining height in the stable state. Large particles were distributed on the top of the scraper, and small particles were distributed at the bottom. With regard to the particle velocity distribution, particles close to the scraper had a high velocity at the bottom, whereas particles at other positions had a lower velocity. The particle velocity distribution in the chute exhibited regional variations, i.e., particles in front of the scraper had the same velocity as the scraper, whereas particles in other regions had lower velocities.

3) There was a quadratic relationship between the mass flow rate and the coefficient of static friction. The mass flow rate reached its peak when the coefficient of static friction was 0.4 .

\section{ACKNOWLEDGEMENTS}

This project was supported by the merit funding for the returned overseas personnel sci-tech activities, Shanxi Province, China (2016), Program for the Outstanding Innovative Teams of Higher Learning Institutions of Shanxi (2014), the Basic Condition Platform Project of Shanxi (2014091016) and the Open Research Fund of Shanxi Key Laboratory of Fully Mechanized Coal Mining Equipment (2015-02).

\section{REFERENCES}

[1] Lodewijks, G. (2002). Two decades dynamics of belt conveyor systems. Bulk Solids Handing, vol. 22, p. 124-132.

[2] Li, G. (2003). Belt conveyor dynamic behavior and associated problems. Bulk Solids Handing, vol. 23, p. 322-327.

[3] Broadfoot, A.R., Betz, R.E. (1997). Prediction of power requirements for a long wall armored face conveyor. IEEE Transaction on Industry Applications, vol. 33, no. 1, p. 80-89, DOl:10.1109/28.567081.

[4] Morley, L.A., Kohler, J.L., Smolnikar, H.M. (1988). A model for prediction motor load for an armored face conveyor drive. IEEE Transaction on Industry Applications, vol. 24, no. 4, p. 649659, D0I:10.1109/28.6117. 
[5] Lodewijks, G. (2004). Strategies for automated maintenance of belt conveyor systems. Bulk Solids Handling, vol. 1, p. 1622.

[6] Xi, P.-Y., Zhang, H.-T., Liu, J. (2005). Dynamics simulation of the belt conveyor possessing feedback loop during starting. Journal of Coal Science \& Engineering, vol. 11, p. 83-85.

[7] Thomas, H., Zhou, M.,Schramm, U. (2002). Issues of commercial optimization software development. Structural Multidisciplinary Optimization, vol. 23, no. 2, p. 97-110, DOI:10.1007/s00158-002-0170-x.

[8] Feriani, A., Perotti, F., Simoncini, V. (2000). Iterative system solvers for the frequency analysis of linear mechanical systems. Computer Methods in Applied Mechanics and Engineering, vol. 190, no. 13-14, p. 1719-1739, Dol:10.1016/ S0045-7825(00)00187-0.

[9] Xue, S.-S., Li, X.-C., Xu, X.-Y. (2016). Fault tree and Bayesian network based scraper conveyer fault diagnosis. Proceedings of the 22 ${ }^{\text {nd }}$ International Conference on Industrial Engineering and Engineering Management, p. 783-795, D0l:10.2991/97894-6239-180-2_74.

[10] Korneev, S.V. (2003). Evaluation of efficiency of controlling the speed of face scraper conveyer. Izvestiya Vysshikh Uchebnykh Zavedenii, Gornyi Zhurnal, (News of the Higher Institutions. Mining Journal), vol. 5, p. 66-71. (in Russian)

[11] Bulin, R., Hajzman, M. (2014). On the modelling of contact forces in the framework of rigid body dynamics. Manufacturing Technology, vol. 14, no. 2, p. 136-141.

[12] Slavković, R., Veg, A., Dučić, N., Slavković, N., Baralić, J., Milićević, I. (2015). Rigid body dynamics in optimization of the machine tool vibroisolation. Tehnicki vjesnik - Technical Gazette, vol. 22, no. 1, p. 87-94, D0l:10.17559/TV20130918225023.

[13] Vasylieva, O.E., Kuzio, I.V. (2014). Optimization of structural elements of drive gearbox shafts of mine scraper conveyors. Naukovyi Visnyk Natsionalnoho Hirnychoho Universytetu, (Scientific Bulletin of National Mining University), no. 3, p. 3745. (in Russian)

[14] Chen, X. Z., Meng, Y., Liu, D.Y., Fan, X. (2012). Analysis on central trough of scraper conveyor by FEM. Coal Mine Machinery, vol. 33, p. 110-112. (in Chinese)

[15] Ren, Z.Q., Chen, J.L. (2013). FEA of scraper conveyer rack rail based on ANSYS. Coal Mine Machinery, vol. 34, p. 99-100. (in Chinese)

[16] Xiao, F.J., Guo, L.J., Li, D.B., Wang, Y.S. (2012). Discrete particle simulation of mixed sand transport. Particuology, vol. 10, no. 2, p. 221-228, D0I:10.1016/j.partic.2011.10.004.

[17] Cundall, P.A., Strack, O.D.L. (1979). A discrete numerical model for granular assemblies. Géotechnique, vol. 29, no. 1, p. 47-65, DOl:10.1680/geot.1979.29.1.47.

[18] Cundall, P.A. (1971). A computer model for simulating progressive large scale movements in blocky systems. Proceedings of the Symposium of the International Society of Rock Mechanics, vol. 2, no. 8.

[19] Landry, H., Laguë, C., Roberge, M. (2006). Discrete element modeling of machine-manure interactions. Computers and Electronics in Agriculture, vol. 52, no. 1-2, p. 90-106, DOI:10.1016/j.compag.2006.02.002.
[20] Marigo, M., Cairns, D.L., Davies, M., Ingram, A., Stitt, E.H. (2011). Developing mechanistic understanding of granular behaviour in complex moving geometry using the discrete element method: Part $\mathrm{B}$ : Investigation of flow and mixing in the turbula (R) mixer. Powder Technology, vol. 212, no. 1, p. 17-24, D0I:10.1016/j.powtec.2011.04.009.

[21] Morrison, R.D., Cleary, P.W., Sinnott, M.D. (2009). Using DEM to compare the energy efficiency of pilot scale ball and tower mills. Minerals Engineering, vol. 22, no. 7-8, p. 665-672, DOI:10.1016/j.mineng.2009.01.016.

[22] Hasan, A., Karrech, A., Chareyre, B. (2017). Evaluating force distributions within virtual uncemented mine backfill using discrete element method. International Journal of Geomechanics, vol. 17, no. 7, D0l:10.1061/(ASCE)GM.19435622.0000850 .

[23] Nandanwar, M., Chen, Y. (2015). Simulation of Triaxial Compression Test for Sandy Loam Soil Using PFC3D, MSc. Thesis, University of Manitoba, Manitoba.

[24] Lim, E.W.C., Wang, C.H., Yu, A.B. (2006). Discrete element simulation for pneumatic conveying of granular material, AlChE Journal, vol. 52, no. 2, p. 496-509, Dol:10.1002/ aic. 10645.

[25] Zuo, S.C., Xu, Y., Yang, Q., Feng, Y.T. (2006). Discrete element simulation of the behavior of bulk granular material during truck braking. Engineering Computations, vol. 23, no. 1, p. 4-15, Dol:10.1108/02644400610638943.

[26] Katterfeld, A., Gröger, T. (2007). Application of the discrete element method - Part 4: Bucket elevators and scraper conveyors. Bulk Solids Handling, vol. 27, p. 228-234.

[27] Katterfeld, A., Gröger, T., Minkin, A. (2007). Discrete element simulation of transfer stations and their verification, 9th International Conference on Bulk Materials Storage, Handling and Transportation, Newcastle, p. 379-385.

[28] Simsek, E., Wirtz, S., Scherer, V., Kruggel-Emden, H., Grochowski, R., Walzel, P. (2008). An experimental and numerical study of transversal dispersion of granular material on a vibrating conveyor. Particulate Science and Technology, vol. 26, no. 2, p. 177-196, Dol:10.1080/02726350801903772.

[29] Hastie, D.B., Wypych, P.W. (2010). Experimental validation of particle flow through conveyor transfer hoods via continuum and discrete element methods. Mechanics of Materials, vol. 42, no. 4, p. 383-394, D0I:10.1016/j.mechmat.2009.11.007.

[30] Derakhshani, S.M., Schott, D.L., Lodewijks, G. (2013). Modeling dust liberation at the belt conveyor transfer point with CFD and DEM coupling method. 11 th International Conference on Bulk Materials Storage, Handling and Transportation, Newcastle.

[31] Yuan, J.M., Yao, H.L., Hu, Z.H., Zhou, J. (2016). The new discharge hopper and EDEM simulation analysis for particles flat accumulation after free falling. International Conference on Advanced Electronic Science and Technology, p. 993-998, DOI:10.2991/aest-16.2016.132.

[32] Mei, L., Hu, J.Q., Yang, J.G., Yuan, J.M. (2016). Research on parameters of EDEM simulations based on the angle of repose experiment. IEEE International Conference on Computer Supported Cooperative Work in Design. p. 570-574, DOI:10.1109/CSCWD.2016.7566053. 